\title{
Article
}

\section{Voltage followers for the design of Sallen-Key Active RC-Filters}

\author{
Chumakov V.E. ${ }^{1}$, Pakhomov I. V. ${ }^{1}$ Titov A. E. ${ }^{2}$, Butyrlagin N. V. ${ }^{1}$, Prokopenko N. N. ${ }^{1}$ \\ ${ }^{1}$ Don State Technical University, Rostov-on-Don, Russia \\ ${ }^{2}$ Southern Federal University, Rostov-on-Don, Russia
}

*E-mail: butyrlagin@gmail.com, ORCID: 0000-0002-6363-5113.

\begin{abstract}
In this paper consider the circuitry of voltage followers (VF) with unitygain, intended for practical use in active Sallen-Key RC-filters (LPF, HPF, BPF, $\mathrm{RF}$ ). The results of research and computer modeling of radiation-resistant and lowtemperature VF in the LTSpice environment on models of CJFET transistors operating under the influence of neutron flux up to $10 \mathrm{e} 14 \mathrm{n} / \mathrm{cm} 2$ and cryogenic temperatures up to $-197^{\circ} \mathrm{C}$ are presented.
\end{abstract}

Keywords: Sallen-Key filters, LPF, HPF, BPF, NF, voltage followers, buffer amplifiers, CJFET, neutron flux, cryogenic temperatures.

\section{Introduction}

The active RC-filters (ARCF) of Sallen-Key family are among the most popular devices in frequency selection for radio engineering, automation and telecommunications [1]. As amplifying elements in ARCF of this class used operational amplifiers with $100 \%$ negative feedback [2] or buffer amplifiers (BA), which implemented on one or several transistors (BJT, CMOS, SOI, etc.). In recent years this area of practical application of the Sallen-Key ARCF family has emerged as an independent subclass of frequency selection devices [3-4] including for work in severe operating conditions.

Practical realization of Sallen-Key filters family on voltage followers (VF) has, in contrast to ARCF Sallen-Key on operational amplifiers (OPA), an important advantage - VF circuits can be performed in the form of the simplest emitter or source followers [5-10]. As a result, such ARCF active elements are distinguished by a wider operating frequency range and low power consumption in comparison with OPA.

The purpose and novelty of this article is to consider the circuitry of voltage followers and their practical use for Sallen-Key ARCF family, including those operating at low temperatures and a neutron flux. 


\section{Typical Architectures Sallen-Key ARCF on base voltage followers}

Currently, a four basic Sallen-Key filter circuits are known, which implemented on the basis of voltage followers (Figure 1) [11].

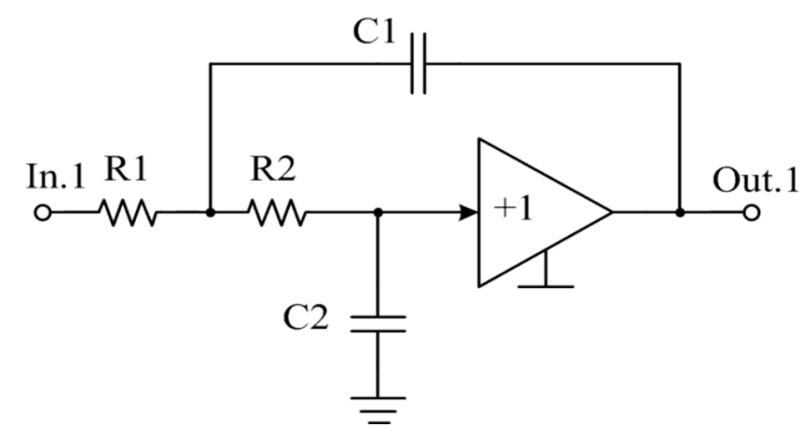

(a)

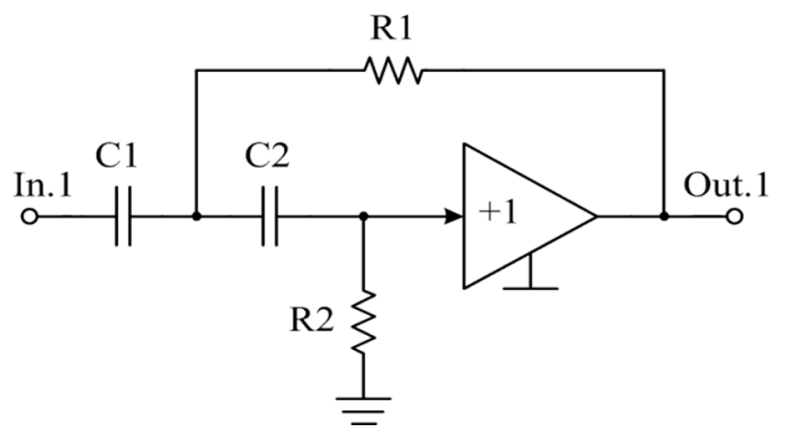

(b)

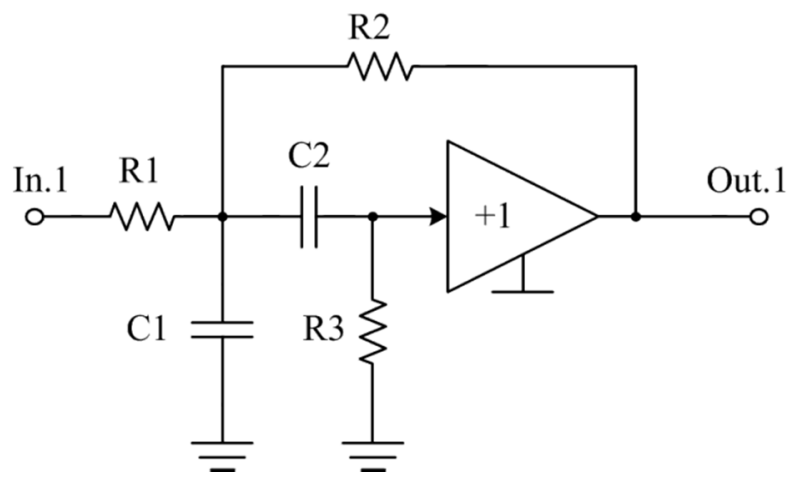

(c)

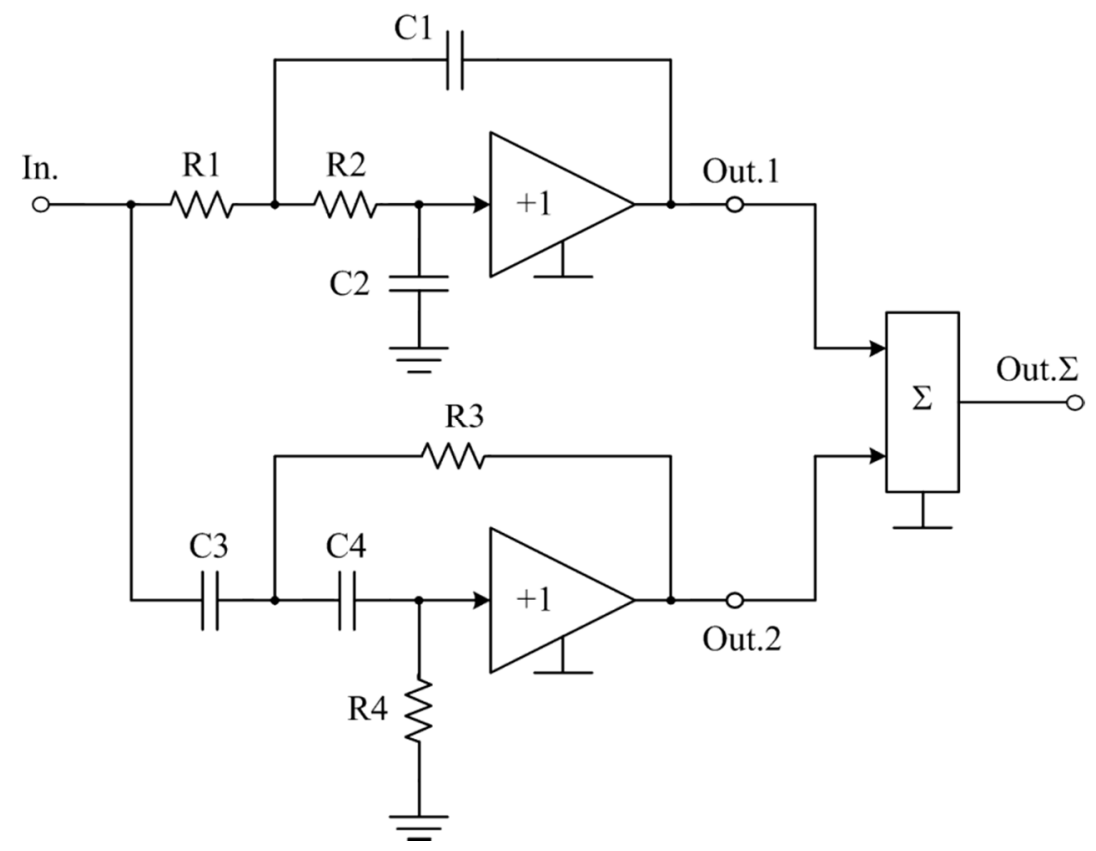

(d)

Figure 1. Circuits of filters Sallen-Key family of a low-pass filter [12] (a), a high-pass filter in the structure [13] (IC5, IC6) (b), a band-pass filter (c), a notch filter [14] (d). 
Below are the basic equations of Sallen-Key ARCF that allow you to choose their settings [11]. So, for the low-pass filter circuit (Figure 1 (a)) the transfer function is determined by the expression

$$
\mathrm{W}(\mathrm{p})=\frac{\mathrm{R}_{1} \mathrm{R}_{2}}{\left(\mathrm{R}_{1} \mathrm{C}_{1}+\mathrm{R}_{2} \mathrm{C}_{2}\right)+\mathrm{R}_{2} \mathrm{C}_{2}-\mathrm{R}_{1} \mathrm{C}_{2}},
$$

then pole frequency $\omega_{p}=\frac{1}{\sqrt{\mathrm{R}_{1} \mathrm{C}_{1} \mathrm{R}_{2} \mathrm{C}_{2}}}$.

The transfer function of the high-pass filter (Figure $1(\mathrm{~b})$ ) is

$$
\mathrm{W}(\mathrm{p})=\frac{\mathrm{p}^{2}}{\mathrm{p}^{2}+\mathrm{p}\left(\frac{1}{\mathrm{C}_{1} \mathrm{R}_{2}}+\frac{1}{\mathrm{C}_{2} \mathrm{R}_{2}}-\frac{1}{\mathrm{C}_{1} \mathrm{R}_{1}}\right)+\frac{1}{\mathrm{C}_{1} \mathrm{R}_{1} \mathrm{C}_{2} \mathrm{R}_{2}}},
$$

and pole frequency $\omega_{\mathrm{p}}=\frac{1}{\sqrt{\mathrm{R}_{1} \mathrm{C}_{1} \mathrm{R}_{2} \mathrm{C}_{2}}}$.

In the band-pass filter circuit (Figure 1 (c)), the transfer function is determined

$$
\mathrm{W}(\mathrm{p})=\frac{\frac{1}{\mathrm{C}_{1} \mathrm{R}_{1}} \mathrm{p}}{\mathrm{p}^{2}+\mathrm{p}\left(\frac{1}{\mathrm{C}_{1} \mathrm{R}_{1}}+\frac{1}{\mathrm{C}_{1} \mathrm{R}_{3}}+\frac{1}{\mathrm{C}_{2} \mathrm{R}_{3}}-\frac{1}{\mathrm{C}_{1} \mathrm{R}_{2}}\right)+\frac{\mathrm{R}_{1}+\mathrm{R}_{2}}{\mathrm{R}_{1} \mathrm{R}_{2} \mathrm{R}_{3} \mathrm{C}_{1} \mathrm{C}_{2}}},
$$

at that pole attenuation $d_{p}=\frac{\frac{1}{C_{1} R_{1}}+\frac{1}{C_{1} R_{3}}+\frac{1}{C_{2} R_{3}}}{\sqrt{\frac{R_{1}+R_{2}}{R_{1} R_{2} R_{3} C_{1} C_{2}}}}$,

and pole frequency $\omega_{p}=\sqrt{\frac{R_{1}+R_{2}}{R_{1} R_{2} R_{3} C_{1} C_{2}}}$.

Figure 2 shows examples of the inclusion of a VF [16] in the structures of a 3rd order Chebyshev low-pass filter (LPF) (Figure 2 (a)), in a 4th order Butteworth LPF (Figure 2 (b)), in a 5th order Bessel LPF (Figure 2 (c)). In a particular case, as buffer amplifiers BA1 and BA2 in the circuit on Figure 2 (c) may be using on op amps with $100 \%$ negative feedback can be used. 


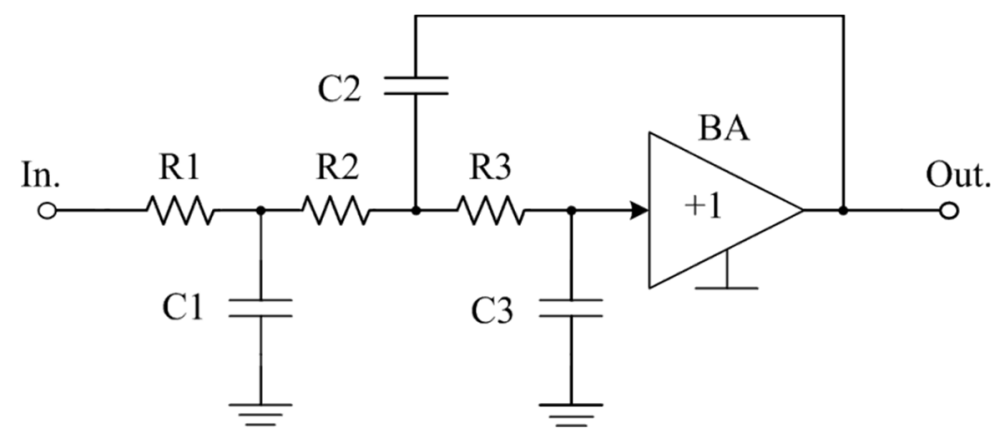

(a)

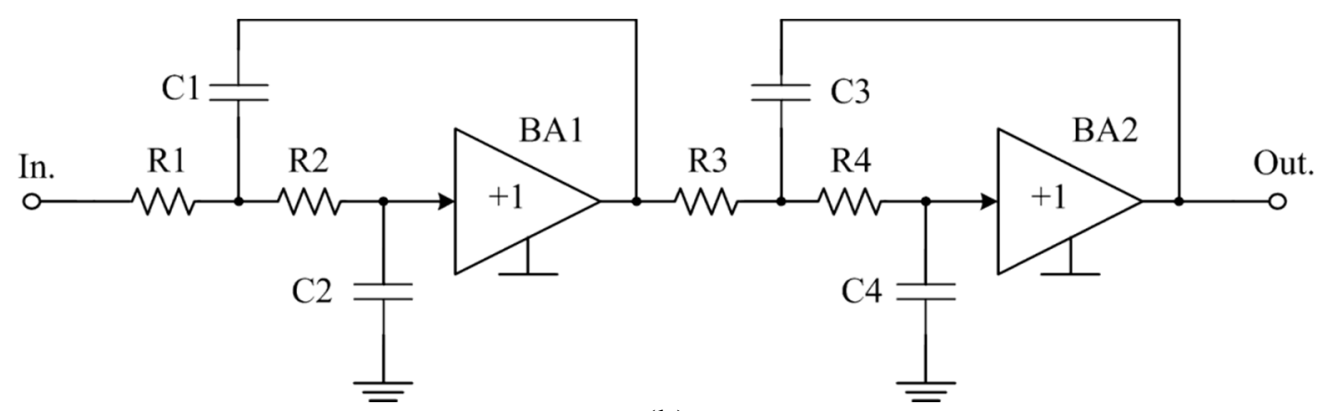

(b)

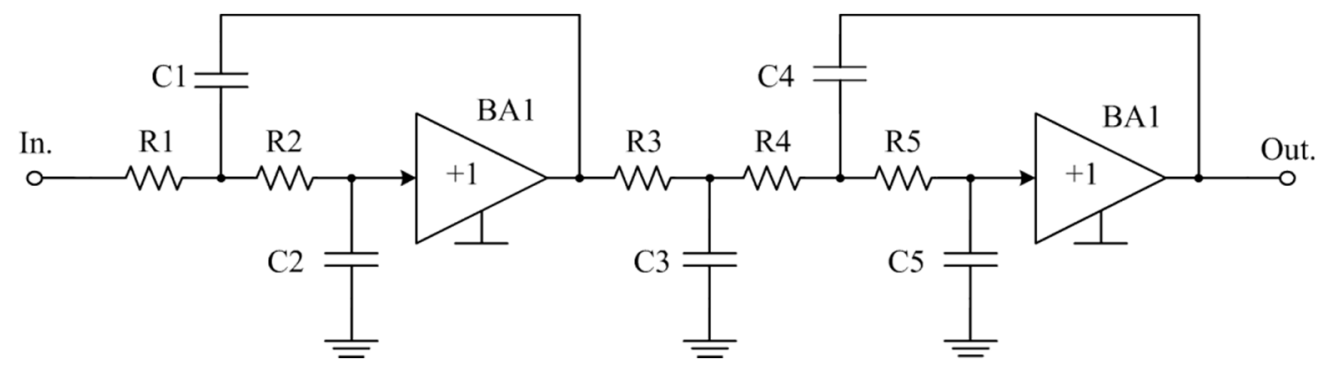

(c)

Figure 2. Examples of the inclusion of VF in the structures of a 3rd order Chebyshev low-pass filter (LPF) (a), of a 4th order Butteworth low-pass filter (b), of a 5th order Bessel low-pass filter (c).

\section{The Voltage Follower Circuits for Sallen-Key Active RC-Filters}

The analysis of the VF circuitry, which are used in Sallen-Key ARCF family [1-4], shows that for these tasks the circuits are used, shown on Figure 3. The voltage followers on Figure 3 (a) and Figure 3 (b) are among the most widespread. Their properties are studied in detail in monographs on analog circuitry [16-17]. The flaw of these circuit solutions is a rather large systematic component of the zero bias voltage $\left(\mathrm{V}_{\text {off }}\right.$ ), which is determined by the emitter-base (gate-source) voltage of the used transistors. 


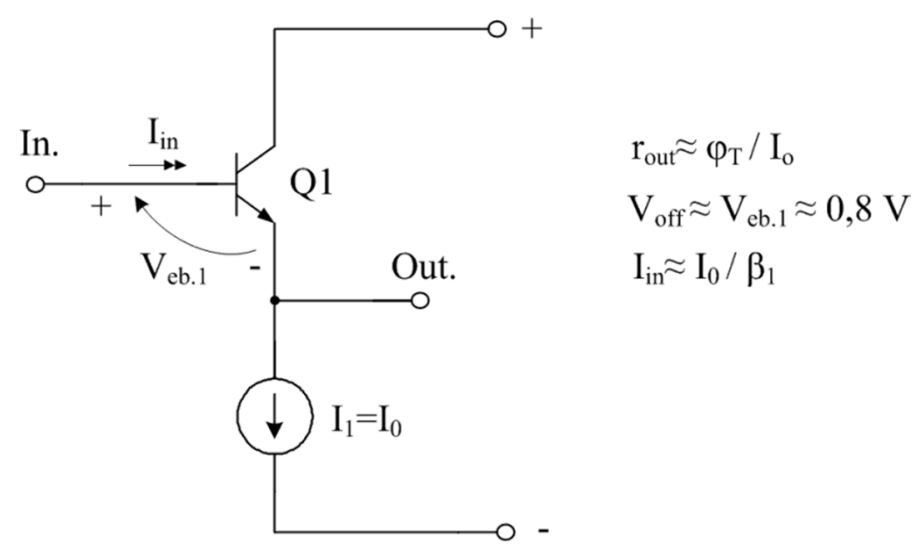

(a)

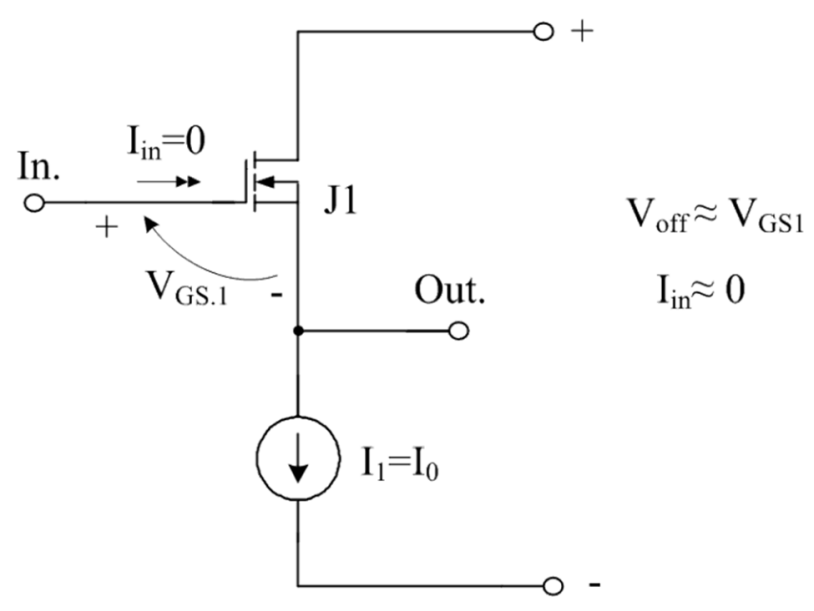

(c)

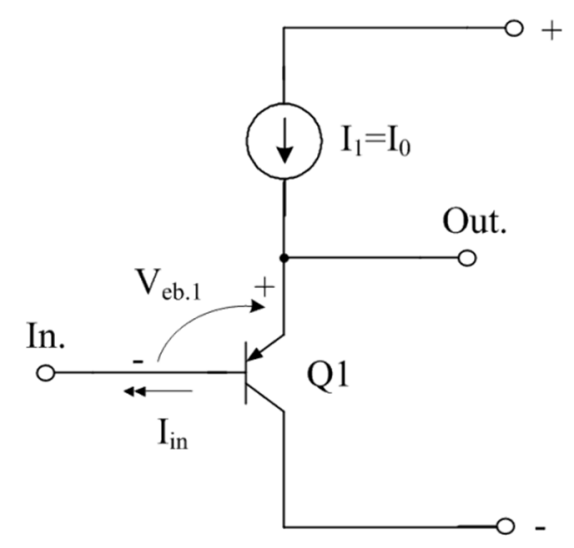

(b)

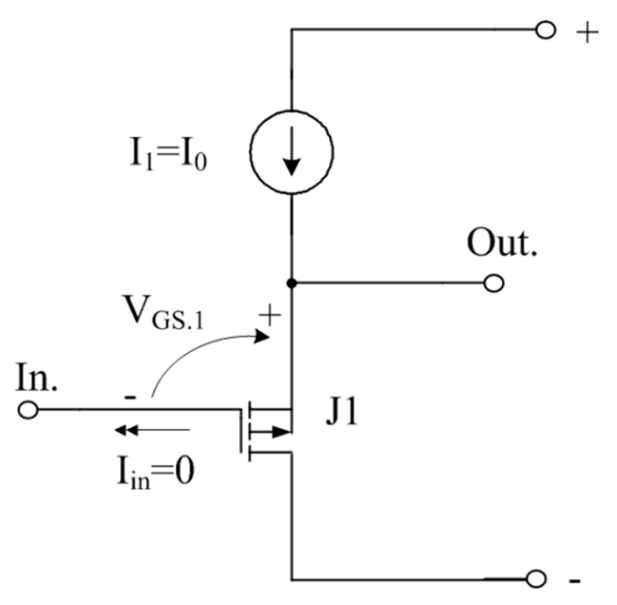

(d)

Figure 3. Voltage followers on bipolar transistors (a, b) and CMOS transistors with an induced channel (c, d).

In VF based on composite transistors (Figure 4 (a), (b), (c)), the difference between the input and output static voltages can be quite small. This is provided by the circuitry of the voltage followers, the topology of the transistors and the applied technological processes. 


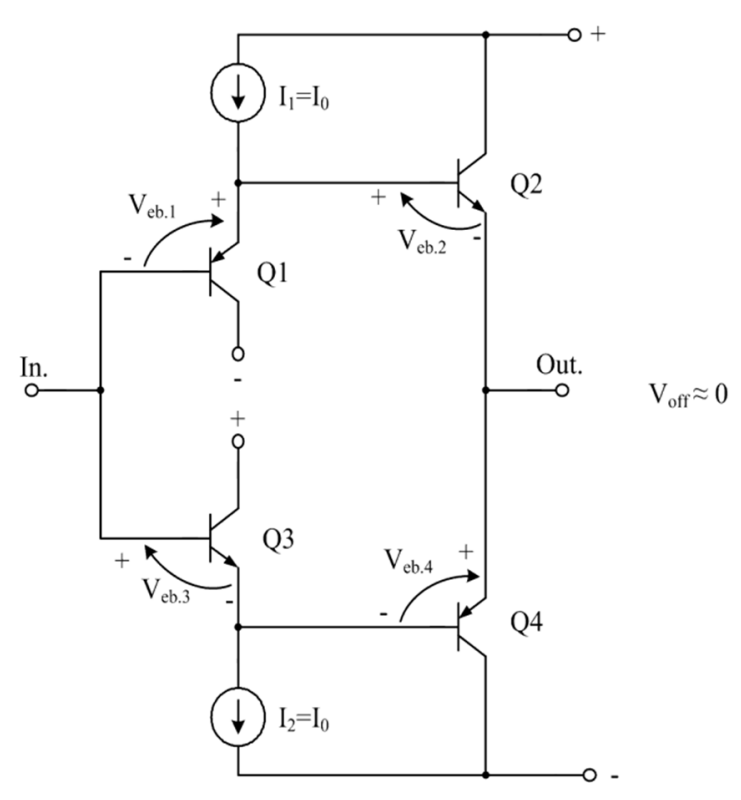

(a)

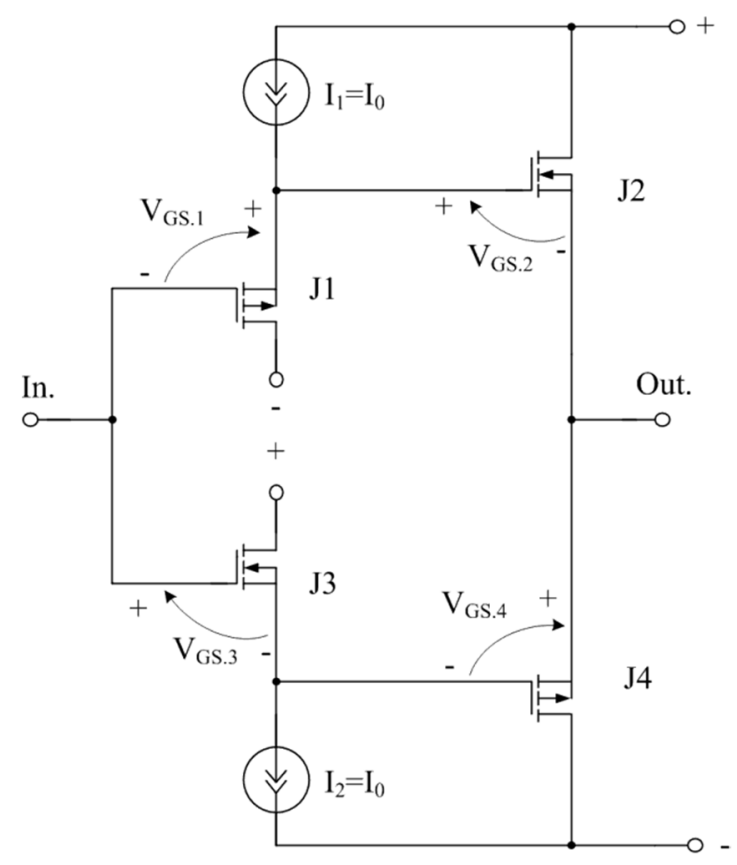

(b)

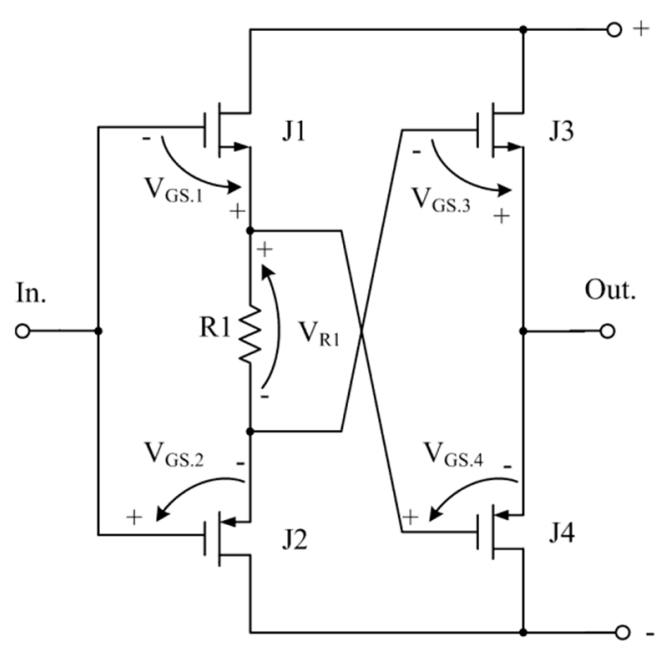

(c)

Figure 4. Voltage followers on composite bipolar transistors (a), CMOS transistors with induced channel (b), CMOS transistors with integrated channel (c).

Construction of VF for the Sallen-Key ARCF family is possible on the basis of the circuitry on simplest OPA with 100\% negative feedback (Figure 5), which allows us to reduce $\mathrm{V}_{\text {off. }}$ However, the frequency characteristics of such voltage followers will be somewhat worse than in control units without feedback. On Figure 5 presented $\mathrm{CM} 1$ is a current mirror. 


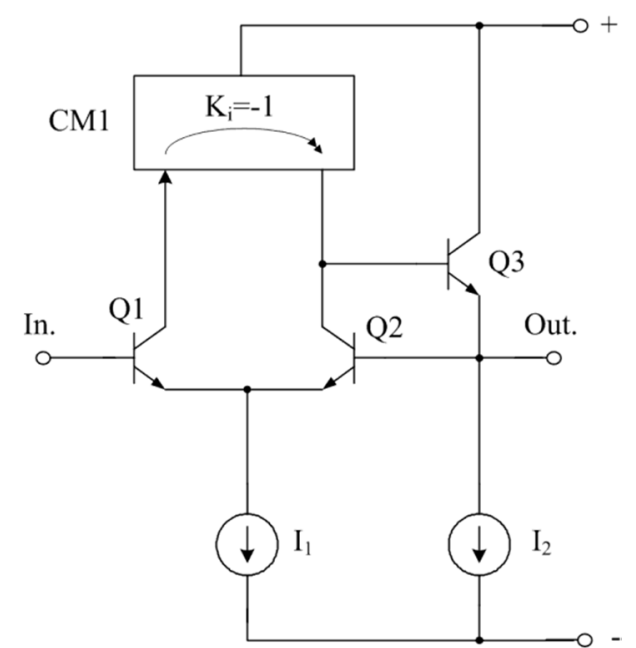

Figure 5. The voltage follower with low voltage offset zero.

To obtain the limiting parameters of the Sallen-Key ARCF family in the frequency range, special VF are designed, including those operating in severe operating conditions [11].

\section{Low-temperature and radiation-resistant voltage follower on complementary field-effect transistors with a control $p-n$ junction}

In Figure 6 and Figure 7 shows two proposed [18-19] circuit modifications of the VF with small $\mathrm{V}_{\text {off, }}$ which made on complementary field-effect transistors with a control pn-junction and provide a low noise level, including when operating in the low temperature range.

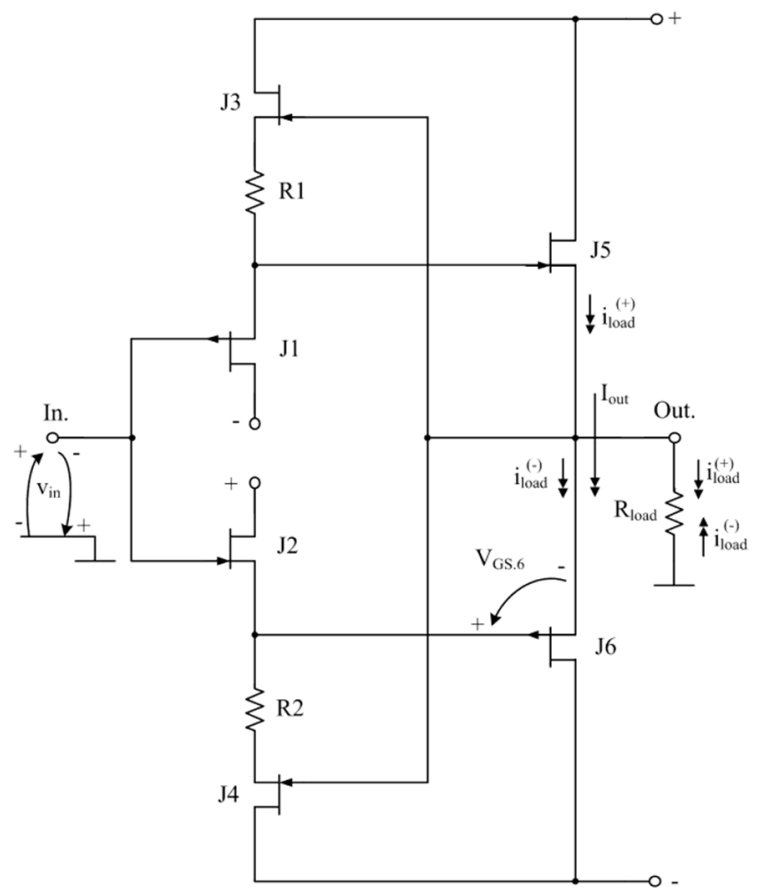

Figure 6. The first modifications of the JFET VF [19]. 


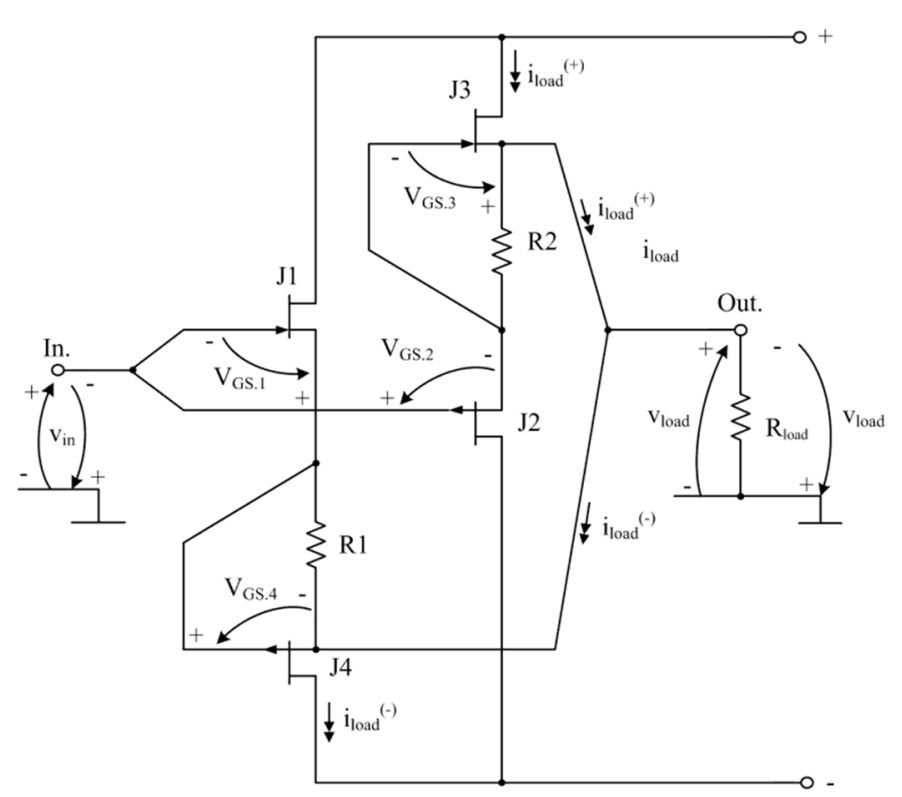

Figure 7. The second modification of the radiation-resistant and low-temperature VF on complementary field-effect transistors [18].

Consider the work of the VF (Figure 7) taking into account the results of modeling its characteristics shown in Figure 8 - Figure 12. In static mode, with a large load resistance $\mathrm{R}_{\text {load, }}$, the source currents of the output and input field-effect transistors $\mathrm{J} 3, \mathrm{~J} 2$, as well as the input and output field-effect transistors $\mathrm{J} 1$, J4 are determined by the formulas

$$
\begin{aligned}
& I_{d .4}=\frac{V_{G S .4}}{R_{1}}=I_{d .1}, \\
& I_{d .3}=\frac{V_{G S .3}}{R_{2}}=I_{d .2} .
\end{aligned}
$$

where $R_{1}, R_{2}$ are the resistances of the corresponding current-stabilizing resistors $\mathrm{R} 1, \mathrm{R} 2$;

$\mathrm{V}_{\mathrm{GS} . i}$ is the gate-source voltage of the $\mathrm{i}$-th field-effect transistor at a given source current.

From formulas (4) and (5) it follows that the static modes of the input fieldeffect transistors J1, J2 can be set independently of each other by currentstabilizing resistors R1, R2. In this case, the static voltage at the output of the VF (with identical drain-gate characteristics of transistors with $p$ - and n-channels) is close to zero:

$$
\mathrm{V}_{\text {load }} \approx \mathrm{V}_{\mathrm{GS} .1}-\mathrm{V}_{\mathrm{GS} .4}=\mathrm{V}_{\mathrm{GS} .3}-\mathrm{V}_{\mathrm{GS} .2} \approx 0 .
$$

In practical VF circuits, due to the difference in threshold voltages of transistors with p- and n-channels in the circuit in Figure 7, the output voltage (the so-called zero bias voltage $\mathrm{VF} \mathrm{V}_{\text {off }}$ ) lies in the ranges of units to tens of millivolts. 
In this case, the numerical values of $\mathrm{V}_{\text {off }}$ can be set, depending on the range of external influences, due to the rational choice of resistances $R_{1}$ and $R_{2}$.

If the input voltage in the circuit (Figure 7) receives a positive increment, then the current in the load $R_{\text {load }}$ also receives a positive increment due to an increase in the source current of the output field-effect transistor J3.

At negative input voltages, the increase in current in the load is provided by increasing the source current of the output field-effect transistor J4.

In Figure 8 shows the static mode of the VF (Figure 7) in LTSpice CAD at $\mathrm{t}=27^{\circ} \mathrm{C}$ (Figure $8(\mathrm{a})$ ) and at $\mathrm{t}=-197^{\circ} \mathrm{C}$ (Figure $8(\mathrm{~b})$ ). In this case, the computer models of JFET transistors presented in [19] were used.

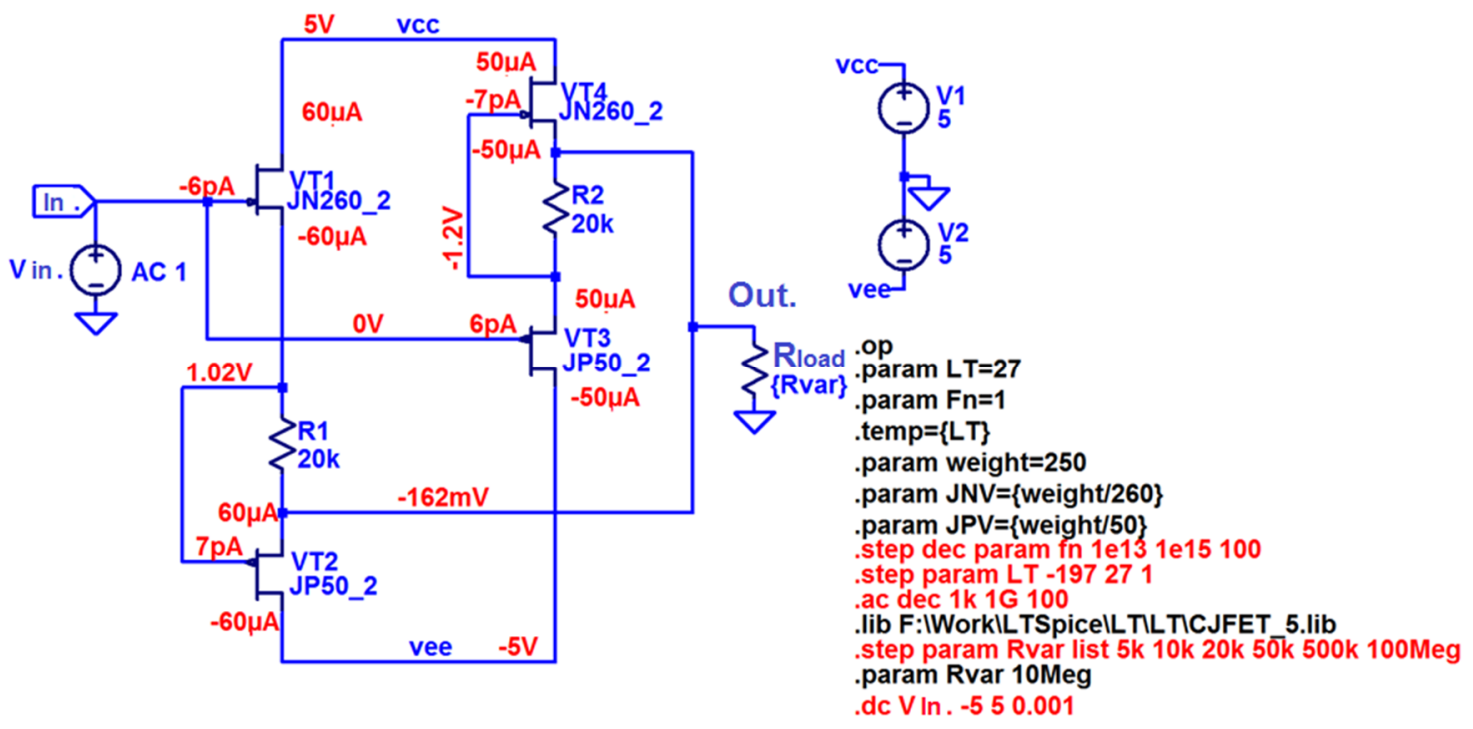

(a)
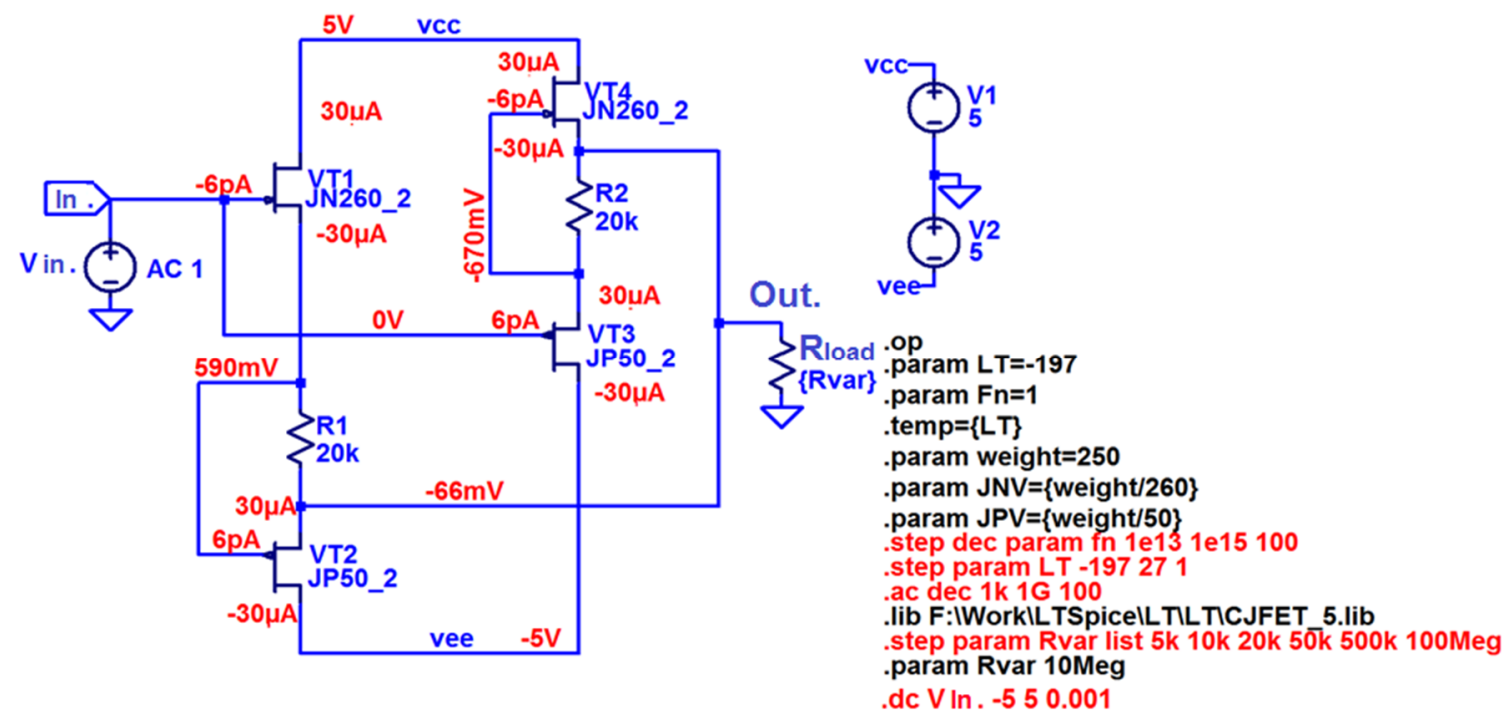

(b)

Figure 8. Static mode of VF (Figure 7) at $\mathrm{t}=27^{\circ} \mathrm{C}$ (a) and $\mathrm{t}=-197^{\circ} \mathrm{C}(\mathrm{b})$. 
In Figure 9 shows the dependence of the output voltage $\left(\mathrm{V}_{\text {out }}\right)$ on the input voltage $\left(\mathrm{V}_{\text {In }}\right)$ VF (Figure 8 (a)) at $\mathrm{t}=27^{\circ} \mathrm{C}$ and different load resistances $\left(\mathrm{R}_{\text {load }}=5 \mathrm{kOhm} / 10 \mathrm{kOhm} / 20 \mathrm{kOhm} / 50 \mathrm{kOhm} / 500 \mathrm{kOhm} / \infty\right)$.

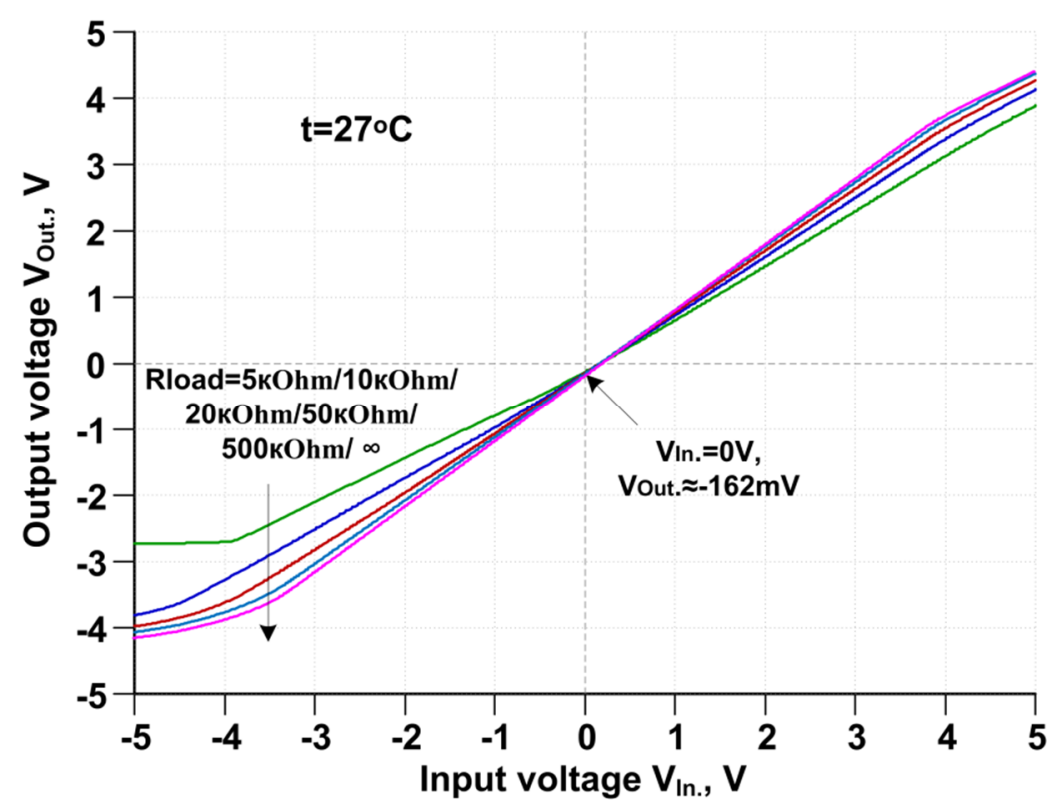

Figure 9. Dependence of the output voltage $\left(\mathrm{V}_{\text {out }}\right)$ on the input voltage $\left(\mathrm{V}_{\text {In }}\right) \mathrm{VF}$ at $\mathrm{t}=27^{\circ} \mathrm{C}$.

In Figure 10 shows the dependence of the output voltage $\left(\mathrm{V}_{\text {out }}\right)$ on the input voltage $\left(\mathrm{V}_{\text {In }}\right) \mathrm{VF}$ on (Figure 8 (b)) at $\mathrm{t}=-197^{\circ} \mathrm{C}$ and different load resistances $\left(\mathrm{R}_{\text {load }}=5 \mathrm{kOhm} / 10 \mathrm{kOhm} / 20 \mathrm{kOhm} / 50 \mathrm{kOhm} / 500 \mathrm{kOhm} / \infty\right)$.

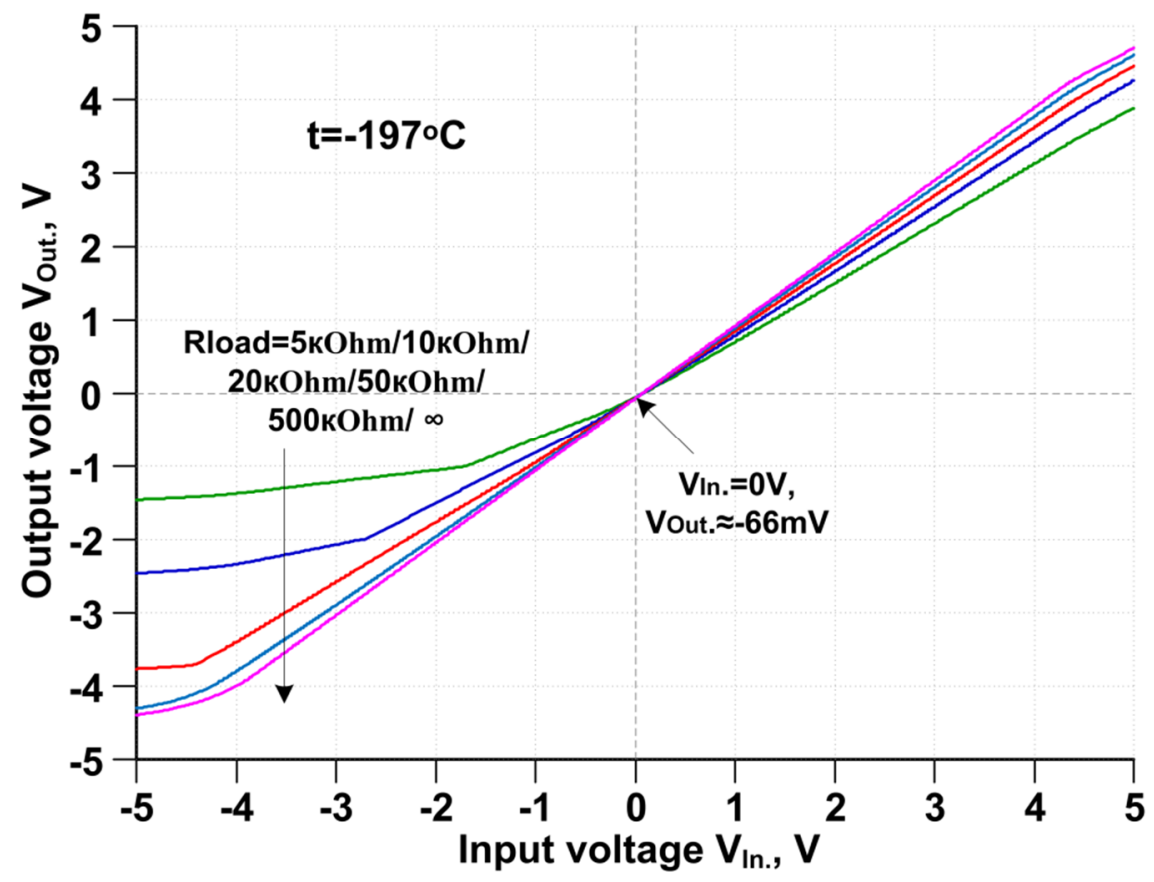

Figure 10. Dependence of the output voltage $\left(V_{\text {out }}\right)$ on the input voltage $\left(V_{\text {In }}\right) \mathrm{VF}$ at $t=-197^{\circ} \mathrm{C}$. 
As follows from the graphs on Figure 9 and Figure 10, the proposed voltage follower provides (at large load resistances $\mathrm{R}_{\text {load}}$ ) maximum output voltages close to the voltages on the positive and negative power supply rails, incl. in the cryogenic temperature range (Figure 11).

In Figure 11 shows the dependence of the output voltage of the VF (Figure 8) on temperature in the range of $-197^{\circ} \mathrm{C} \div+27^{\circ} \mathrm{C}$ at zero input voltage $\left(\mathrm{V}_{\text {in }}=0 \mathrm{~V}\right)$ and load resistance $\mathrm{R}_{\text {load }}=\infty$.

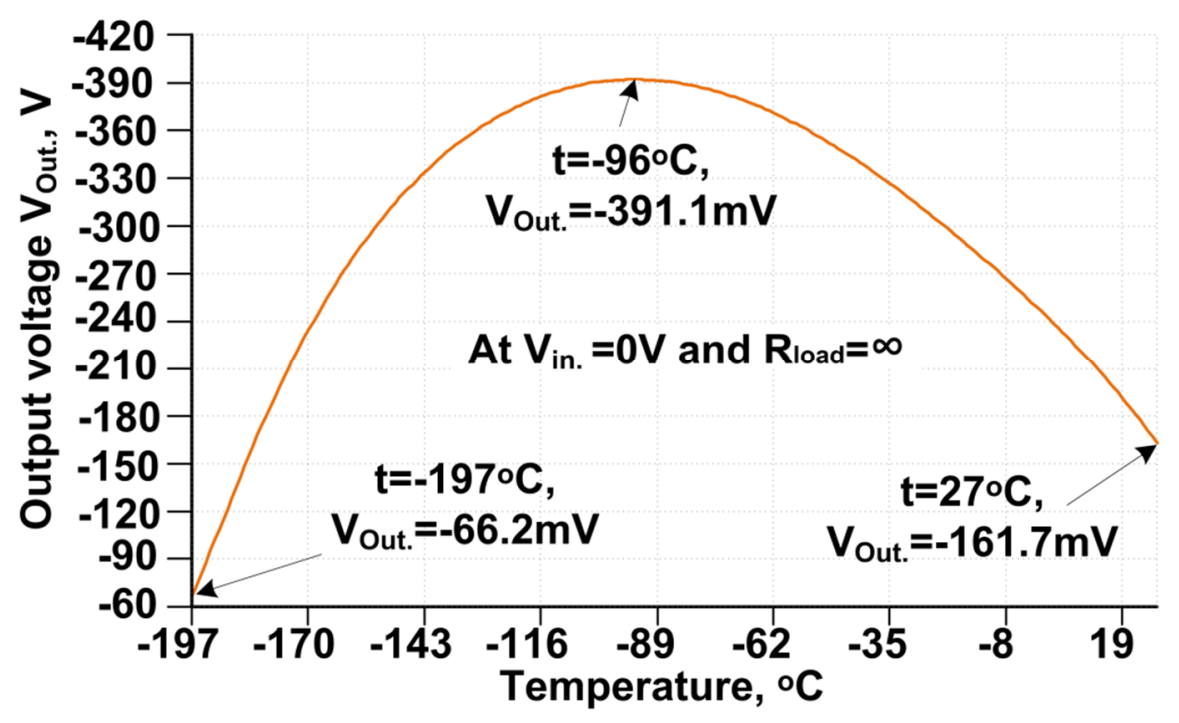

Figure 11. Dependence of the output voltage of the VF on temperature.

In Figure 12 shows the dependence of the output voltage of the VF (Figure 8) from the neutron flux in the range $\mathrm{Fn}=1 \mathrm{e} 13 \div 1 \mathrm{e} 15 \mathrm{n} / \mathrm{cm} 2$ at zero input voltage $\left(\mathrm{V}_{\text {In }}=0 \mathrm{~V}\right)$ and load resistance $\mathrm{R}_{\text {load }}=\infty$. From the graphs in Figure 11 it follows that the proposed VF circuit is efficient in a wide range of changes in the neutron flux.

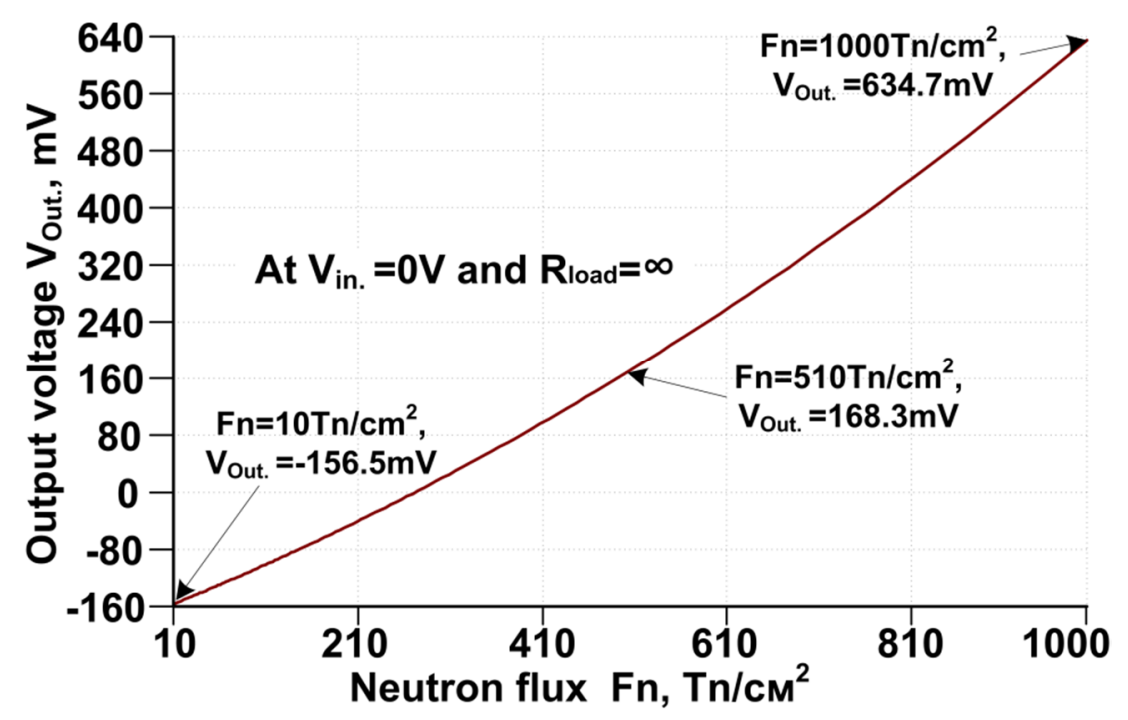

Figure 12. Dependence of the output voltage of the VF on temperature $t=27^{\circ} \mathrm{C}$. 


\section{Conclusion}

The main circuits of voltage follower for Sallen-Key active RC-filters family are considered. Computer simulation shows that the proposed versions of the CJFET VF construction can find application in low-temperature and radiationresistant analog devices [20]. At the same time, due to the appropriate choice of frequency-setting resistors and capacitors in the above-mentioned ARCF circuits, various amplitude-frequency characteristics are realized (Chebyshev, Butterworth and Bessel filters).

Funding: The research has been carried out at the expense of the Grant of the Russian Science Foundation (project No. 18-79-10109-P).

Conflicts of Interest: The author declares no conflict of interest.

\section{References}

1. I. Campanu, T. Salajan, R. Onet and M. Neag, "Comparative analysis of four second-order OA-RC polyphase filters for an ISM Low-IF receiver," CAS 2012 (International Semiconductor Conference), 2012, pp. 385-388, doi: 10.1109/SMICND.2012.6400753.

2. I.M. Dobush et al., "Automated synthesis and measurement of broadband CMOS buffer amplifier 1-5 GHz," 2017 International Siberian Conference on Control and Communications (SIBCON), 2017, pp. 1-4, doi: 10.1109/SIBCON.2017.7998526.

3. D. Denisenko, N. Prokopenko, Y. Ivanov and I. Pakhomov, "Generalized Structure of Active RC Filters with Independent Tuning of Pole Frequency, Pole Q-Factor and Transfer Ratio," 19th IEEE EAST-WEST DESIGN \& TEST SYMPOSIUM (EWDTS-2021), September 10-13, 2021, Batumi, Georgia, p. 268-272, doi: 10.1109/EWDTS52692.2021.9581023.

4. K. Nikolić, J. Radić, "A tunable bandwidth 6th-order active low-pass filter in 0.18 um CMOS technology," 2020 23rd DDECS, Novi Sad, Serbia, 2020, pp. 1-2. doi: 10.1109/DDECS50862.2020.9095683.

5. O. Eoin, “Low noise lowpass filter,” U.S. Patent 2006186951, Aug. 24, 2006.

6. P.C. Van, G. Torfs, J. Bauwelinck, J.Vandewege, "Two stage source-follower based filter," U.S. Patent 9124251, Sep. 1, 2015. 
7. L. I-Hsiang, P. Tzu-Wang, Yi Z., "Fm transmitter and non-fm receiver integrated on single chip," CN Patent 102217204, Dec. 10, 2011.

8. J. Cowles, "Filter circuits with emitter follower transistors and servo loops," US 9614496, Apr. 04, 2017.

9. T.L. Huynh, A. Gercekci, A.D. Newton, "Adaptive radio frequency (RF) filter," U.S. Patent 7.835.434, Nov. 16, 2010.

10. A.V. Bugakova, A.E. Titov, N.N. Prokopenko, "Low-temperature and radiation-resistant voltage follower on complementary field-effect transistors with a control PN-junction for design tasks of active RC-filters," RU Patent 2723673, Jun. 17, 2020.

11. D. Self, "The Design of Active Crossovers," in Routledge, 2nd Ed., 2018, 698 p. doi: 10.4324/9781315187891.

12. A. Hernández-Padilla Reporte de formación complementaria en área de concentración en Sistemas Embebidos y Telecomunicaciones. - 2021, p. 13, Figura. 3.1b (URI https://hdl.handle.net/11117/6471, Trabajo de obtención de grado, Maestría en Diseño Electrónico. Tlaquepaque, Jalisco: ITESO

13. A. N. Thiele, "Crossover filter system and method," U.S. Patent 6.854.005, Feb. 08, 2005.

14. B. Carter, "Filter Design in Thirty Seconds," SLOA093, Application Report, Texas Instruments, 2001, 14 p. [Online]. https://www.vyssotski.ch/BasicsOfInstrumentation/FilterDesignIn30Seconds. pdf (accessed on 23 Nov. 2021).

15. Analog filters chapter 8 analog filters. [Online]. https://www.analog.com/media/en/training-seminars/design-handbooks/BasicLinear-Design/Chapter8.pdf (accessed on 23 Nov. 2021).

16. A Designer's Guide to Instrumentation Amplifiers, 3 RD Edition. [Online]. https://www.analog.com/media/en/training-seminars/design-

handbooks/designers-guide-instrument-amps-complete.pdf (accessed on 23 Nov. 2021).

17. Other linear circuits December 2018. [Online]. https://www.analog.com/media/en/training-seminars/design-handbooks/BasicLinear-Design/Chapter2.pdf (accessed on 23 Nov. 2021).

18. D.G. Drozdov, A.V. Bugakova, N.N. Prokopenko, "High-speed output stage of analog ICs on complementary field-effect transistors with a control p-n junction for operation at low temperatures," RU Patent 2711725, Jun. 17, 2020. 
19. O. V. Dvornikov, V. L. Dziatlau, N. N. Prokopenko, K. O. Petrosiants, N. V. Kozhukhov and V. A. Tchekhovski. The accounting of the simultaneous exposure of the low temperatures and the penetrating radiation at the circuit simulation of the BiJFET analog interfaces of the sensors // 2017 International Siberian Conference on Control and Communications (SIBCON), Astana, Kazakhstan, 2017, pp. 1-6. DOI: 10.1109/SIBCON.2017.7998507.

20. D.Yu Denisenko, N.N. Prokopenko, E.A. Zhebrun, G.A. Svizev, LowTemperature KHN Active RC-Filter Circuit with the Effect of Compensation of Gain Areas of Operational Amplifiers // Problems of advanced micro- and nanoelectronic systems development, Moscow, Russia, 2019, pp. 2-7. DOI: $10.31114 / 2078-7707-2019-3-2-7$. 